\title{
Characteristic analysis of layered PMSEs measured with different elevation angles at VHF based on an experimental case
}

\author{
ShuCan Ge ${ }^{1}$, HaiLong $\mathrm{Li}^{1 *}$, Bin $\mathrm{Xu}^{2}$, Tong Xu' ${ }^{2}$, Lin Meng ${ }^{1}$, MaoYan Wang ${ }^{3}$, Abdel Hannachi ${ }^{4}$, MengYan Zhu², \\ Lina Broman4, Safi Ullah', and Abdur Rauf1 \\ 'School of Electronic Science and Engineering, University of Electronic Science and Technology of China, Chengdu 610054, China; \\ ${ }^{2}$ National Key Laboratory of Electromagnetic Environment, China Research Institute of Radiowave Propagation, Qingdao 266107, China; \\ ${ }^{3}$ School of Physics, University of Electronic Science and Technology of China, Chengdu 610054, China; \\ ${ }^{4}$ Department of Meteorology, Stockholm University, Stockholm SE-106-91, Sweden
}

Key Points:

- The PMSEs peak power and strongest PMSEs average power occur at the same elevation angles.

- The strongest echoes occur at off-vertical elevation angle when there is layered PMSEs.

- Anisotropic scattering theory maybe dominates the layered PMSEs.

Citation: Ge, S. C., Li, H. L., Xu, B., Xu, T., Meng, L., Wang, M. Y., Hannachi, A., Zhu, M. Y., Broman, L., Ullah, S. and Rauf, A. (2021). Characteristic analysis of layered PMSEs measured with different elevation angles at VHF based on an experimental case. Earth Planet. Phys., 5(1), 42-51. http://doi.org/10.26464/epp2021001

\begin{abstract}
Polar Mesosphere Summer Echoes (PMSEs) are very strong radar echoes observed at altitudes near the polar summer mesopause. One of the essential properties of these radar echoes is that they can give useful diagnostic information about the physics of the scattering process. In this paper, the related characteristics of PMSEs measured with the European Incoherent SCATter Very High Frequency (EISCAT VHF) $224 \mathrm{MHz}$ radar on 13-15 July 2010 are studied at different elevation angles from $78^{\circ}$ to $90^{\circ}$. It is found that the PMSEs peak power and strongest PMSEs average power occur at the same elevation angles. Also interesting is that the strongest PMSEs occur at off-vertical angles when a PMSEs has a layered (multilayer) structure. And reflection may have more significant effects on PMSEs when there are double or multilayer PMSEs. Possible explanations regarding these observations are discussed.
\end{abstract}

Keywords: Polar Mesosphere Summer Echoes; off-vertical angles; layered structure

\section{Introduction}

Polar Mesosphere Summer Echoes (PMSEs) are extremely strong radar echoes observed from 80 to $90 \mathrm{~km}$ at high latitudes in the Northern and Southern Hemispheres during summer. Nowadays it is known that PMSEs are due to scattering from fluctuations in electron density caused by atmospheric turbulence in the presence of ice particles formed from water vapor and ice particles in noctilucent clouds forming at low temperatures in the local summer mesopause. These PMSEs events have attracted considerable interest from the scientific community over the four decades since 1981 when a PMSEs was first reported (Ecklund and Balsley, 1981). There is no consensus, however, concerning the exact generation mechanisms, such as turbulent backscatter and Fresnel reflection theory. To further investigate the generation mechanism of PMSEs, theoretical and experimental studies have been carried out by many researchers (e.g., Hocking et al., 1986; Reid et al., 1988; Pfaff et al., 2001; Zecha et al., 2001; Chilson et al., 2002;

Correspondence to: H. L. Li, hailong703@163.com

Received 13 JUL 2020; Accepted 28 AUG 2020.

Accepted article online 21 SEP 2020.

(C) 2021 by Earth and Planetary Physics.
Bremer et al., 2006; Smirnova et al., 2010, 2011, 2012; Li Q and Rapp, 2013; Chau et al., 2014; Yi W et al., 2017, 2018). Sommer et al. (2016a) suggest that PMSEs consist of nonhomogeneous isotropic scattering. Furthermore, PMSEs occur in horizontally contiguous areas or patches, which can be smaller than 1 to several kilometers in diameter and which are subject to strong spatial and temporal changes (Sommer et al., 2016b). On the angular dependence of PMSEs, actually, the obtained radar observations in the mesosphere have not been consistent with the two classical extreme models: turbulent volume isotropic scattering and Specular Fresnel reflection. In view of these empirical observations, Swarnalingam et al. (2011) suggested a new model for anisotropic turbulence and Fresnel scattering. The angular dependence of PMSEs is an important discovery that has not yet received proper attention. The characteristics of PMSEs with different elevation angles are a property of the scatterer, and describe the variation of scattered power with respect to the incident angle.

The feature of PMSEs with different elevation angles may be obtained by two different methods: (1) by comparing the radar echo strengths from vertical and off-vertical radar beams; and (2) by using spaced antennas (SA) in beam estimates. Zecha et al. (2001) used both Doppler Beam Swinging (DBS) and Full Correlation 
Analysis (FCA) methods for measuring the angular dependence of PMSEs and found that the results obtained from these two methods differ significantly. We will not touch on these methods here, but will analyze the related characteristics of PMSEs with different elevation angles. The main method used for vertical measurements and associated bias was to analyze comprehensively the PMSEs directivity characteristics obtained from the multiple antenna beams of the same radar. We note that the PMSEs characteristics detected by $224 \mathrm{MHz}$ and $50-53.5 \mathrm{MHz}$ radars are known to be different. The PMSEs experiments described here employed the EISCAT VHF $224 \mathrm{MHz}$ radar with vertical and oblique beams. Based on this, the experiments were performed at elevation angles $78^{\circ}-90^{\circ}$ (deviation from the vertical direction of $0^{\circ}-12^{\circ}$ ). La Hoz et al. (2014) made measurements of PMSEs by a bistatic radar system and found a high degree of isotropy in the turbulent irregularities that produce the scattering. $\mathrm{Li} \mathrm{H}$ et al. (2018) collected PMSEs data by intersecting the antenna beam from the zenith direction and found that the echo intensity received by the oblique beam is larger than that obtained from the vertical beam.

In this paper, we use data from the EISCAT VHF radar located near Tromsø in Norway on 13-15 July 2010 to explore the related characteristics of PMSEs with different elevation angles. Our main focus is on echo intensities from the vertical and off-vertical radar beams with changing elevation angle. Additional information on the generation mechanism of PMSEs may be gained, which can improve our understanding of the full process. This report is organized as follows. Section 2 describes the experiment configuration. Section 3 describes the characteristics of PMSEs with different elevation angles by analyzing the results of the 3-days of observational experiments. Section 4 discusses PMSEs profiles and offers part of the explanation; conclusions are given in the last section.

\section{Experimental Configuration}

The experimental case (13-15 July 2010) was chosen because few continuous observations of PMSEs behavior have been made at different elevation angles and of simultaneously layered PMSEs. The experiments were carried out by EISCAT VHF $224 \mathrm{MHz}$ radar. The monostatic VHF radar in Troms $\varnothing\left(69^{\circ} 35^{\prime} \mathrm{N}, 19^{\circ} 14^{\prime} \mathrm{E}\right)$ operates in the $224 \mathrm{MHz}$ band with peak transmitter power of $1.5 \mathrm{MW}$ and $120 \mathrm{~m} \times 40 \mathrm{~m}$ parabolic cylinder antenna, which is subdivided into four sectors. It can be steered mechanically in the meridional plane from vertical to $60^{\circ}$ north of the zenith; limited east-west steering is also possible using alternative phasing cables (for more details: https://eiscat.se/scientist/document/experiments/). Based on the occurrence rate of PMSEs, the experiments were continuously conducted on 13-15 July 2010. At the same time, EISCAT VHF and MORRO radars were used to detect and monitor the intensities of radar echoes.

\section{Data Presentation}

In order to get more detailed information on PMSEs, the off-vertical elevation angles were gradually changed during the experiments, and the biggest off-vertical elevation angles of the experiments were different. In the experiment, the deflection of the radar beam was limited to the north-south direction, and the measurement mode was conducted in such a way that the direction of the radar beam jumped periodically between the vertical and a certain off-zenith angle (see next section). In order to facilitate the observation of PMSEs, the radar working mode used in the experiment was pmsecompl64 mode which is an upgraded version of the arc_dlayer mode. The temporal and spatial resolutions of this mode are respectively $4 \mathrm{~s}$ and $300 \mathrm{~m}$. The height range of this mode is $59.7-139.5 \mathrm{~km}$. Besides, in order to reduce the variance of the data measurement, some abnormal echoes were removed, which are related to the meteor, whose effects are not considered to be a PMSEs and are thus neglected in later discussion. The effects of noise have also been removed. The experiments consist of observing 15 cycles with elevation angles ranging from $84^{\circ}$ to $90^{\circ}$ on the $13^{\text {th }}$ of July 2010 and 24 cycles from $78^{\circ}$ to $90^{\circ}$ on the $14^{\text {th }}$ and $15^{\text {th }}$ of July 2010 . The results are analyzed and discussed in detail in the next sections.

\section{Results}

In this section, the experimental results on 13, 14, and 15 July 2010 are analyzed, respectively, because the increment and range of elevation angle observations were different on different days. The antenna beam was traversed from $90^{\circ}$ to $84^{\circ}$ off the zenith on 13 July, and from $90^{\circ}$ to $78^{\circ}$ on the following two days.

\subsection{Results from PMSEs Experiment on 13 July 2010}

On 13 July 2010, the experiment began at 10:38 UT. The PMSEs measurements started first with a vertical elevation angle $\left(90^{\circ}\right)$, which was then changed by increments of $2^{\circ}$, to yield observation angles from and back to $90^{\circ}$ (i.e. $90^{\circ} \rightarrow 88^{\circ} \rightarrow 86^{\circ} \rightarrow 84^{\circ} \rightarrow 86^{\circ} \rightarrow$ $88^{\circ} \rightarrow 90^{\circ}$ ). The process is considered here as a two-cycle process, although it was in fact conducted as a single cycle, as the observation angle went down from $90^{\circ}$ and then back up to $90^{\circ}$. It took about 30 seconds to steer the radar from one angle to another, and the radar was made to observe each PMSEs, statically, for about $2.5 \mathrm{~min}$, so one observation cycle took $6 \times(0.5+2.5) \mathrm{min}=$ $18 \mathrm{~min}$.

Since the radar antenna during the experiment on 13 July 2010 did not return to the vertical angle, the resulting incomplete period was ignored. Thus only 15 complete measurement cycles on 13 July are analyzed. In order to better analyze the experiment, we consider four cycles as a whole. Since there are only 15 cycles on 13 July 2010, the last part of the experiment is limited to three complete cycles. The upper panel of Figure 1a shows the PMSEs intensity over the time interval from $10: 38$ to $13: 00$ at $82-92 \mathrm{~km}$; the lower panel shows the associated radar antenna elevation angles used in the experiment $\left(84^{\circ}, 86^{\circ}, 88^{\circ}, 90^{\circ}\right)$. The four panels of Figure $1 \mathrm{~b}$ show PMSEs median power versus the antenna elevation angle during the first four measurement cycles. By comparing the panels of Figure $1 \mathrm{~b}$, we see that there is only one maximum of the median value of PMSEs power in each cycle. By analyzing Figure 1, we observe that the PMSEs phenomenon has an obviously layered structure; most of the time a double-layer PMSEs is prominent during the experiment. The intensity of echoes was stronger at 10:40-11:40 UT compared to other times. It can be seen that the double-layer PMSEs often weakened or disappeared at different times in the upper or lower layers. Notice also 

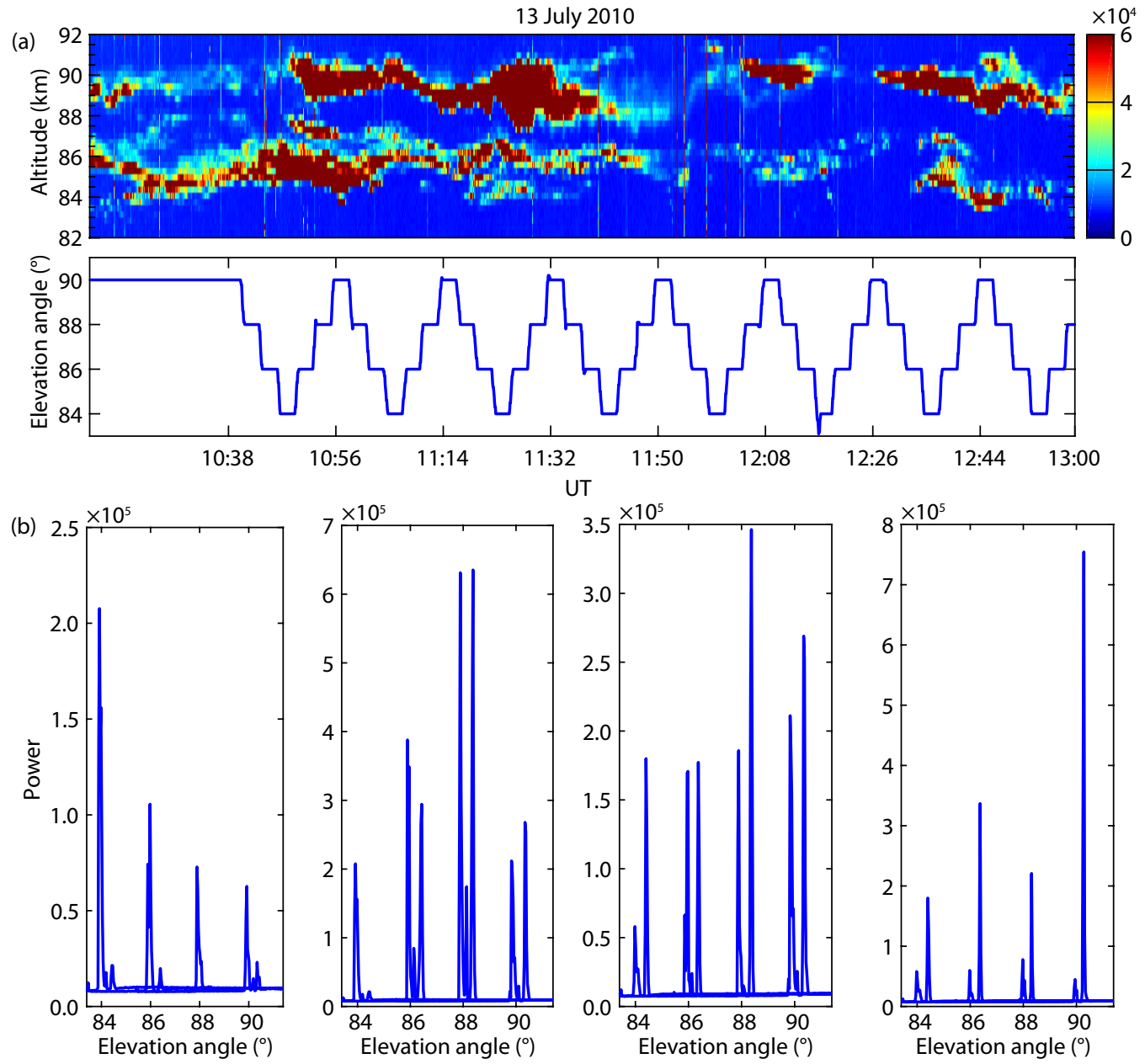

Figure 1. PMSEs observations by EISCAT VHF radar at 10:38-13:00 UT on 13 July 2010. The scale of the PMSEs intensity (as measured by power spectral density) is arbitrary. (a) Height-time contour plot for PMSEs backscatter power spectral density in arbitrary unit (upper panel), and the corresponding elevation angles observing the PMSEs (bottom panel). (b) Median PMSEs power intensity versus elevation angles during the four measurement cycles.

that the upper layer of the PMSEs was generally higher than 90 $\mathrm{km}$ when the PMSEs exhibited multiple layers. This observation differs from PMSEs heights (below $90 \mathrm{~km}$ ) described previously in the literature.

The variation of PMSEs power with elevation angle over the time interval 11:38-13:00 UT on 13 July 2010 is shown in Figure 2. The variability of the mean PMSEs power with time at different elevation angles is given in Figure 3. The radar steering time was not always constant for each changing elevation, but every steering was completed in $140 \mathrm{~s}$ for all the cycles. From Figure $2 \mathrm{a}$, the PMSEs power at elevation angle $86^{\circ}$ is obviously higher than that at any other elevation. That is, the strongest PMSEs occurred at off-vertical angles on 13 July 2010, when there were layered PMSEs events.

\subsection{Results from PMSEs Experiments on 14 and 15 July 2010}

In order to study in more detail the characteristics of PMSEs with different elevation angles, on 14 and 15 July we expanded the range of elevation angles for the experiments; the elevation angle was changed by $4^{\circ}$ increments to yield observations starting from and returning to $90^{\circ}$, i.e. $90^{\circ} \rightarrow 86^{\circ} \rightarrow 82^{\circ} \rightarrow 78^{\circ} \rightarrow 82^{\circ} \rightarrow 86^{\circ} \rightarrow 90^{\circ}$. The same rotation style and observation mode as that of 13 July 2010 was adopted; 16 and 8 complete cycles of measurements, respectively, were conducted on the $14^{\text {th }}$ and $15^{\text {th }}$ and the experimental results were explored.

The first four cycles analyzed as a whole are shown in Figures 4-9, Figures 4-6 representing the results for 14 July and Figures 7-9 showing the results for 15 July. The upper panels of Figures $4 a$ and 7a display the PMSEs power observed by radar (as in the upper panel of Figure 1a). The lower left panels of Figures 4 and 7 show the antenna elevation angles of the radar corresponding to the upper left panel of the same figures. The four panels of Figure $4 \mathrm{~b}$ show the median power at the considered elevation angles. Figure 4 shows that PMSEs have obvious stratification and occur mostly in a double-layer structure. There is only one maximum median value of PMSEs power in the panels of Figure $4 \mathrm{~b}$, but the maximum median powers at $90^{\circ}$ and $82^{\circ}$ of the third panel are approximately equal. This suggests that the maximum median of PMSEs intensity may occur at two angles. 

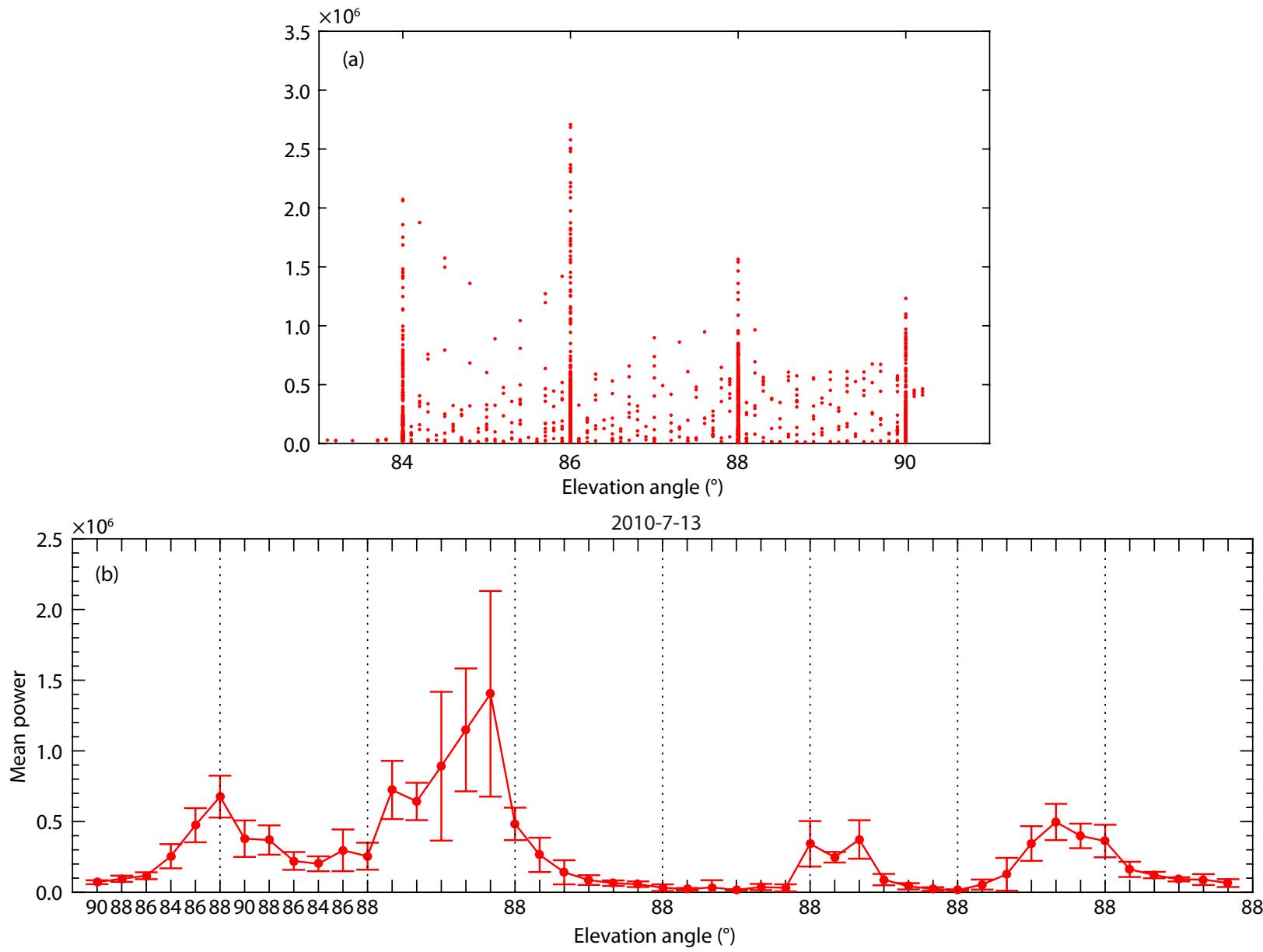

Figure 2. (a) PMSEs power versus elevation angles over the time interval 10:38-13:00 on 13 July 2010. (b) Errorbar of PMSEs power versus elevation angles over the time interval 10:38-13:00 (fifteen measurement cycles) on 13 July 2010. Black dotted lines are the boundary line for every two measurement cycles. The power value is the average of the power measured at the current elevation angle.

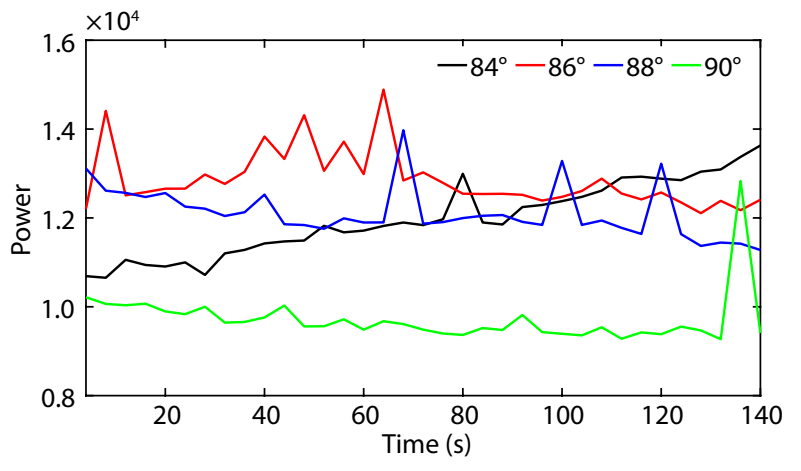

Figure 3. Mean PMSEs power versus the time of one cycle (the shortest cycle) for different elevation angles $\left(84^{\circ}, 86^{\circ}, 88^{\circ}, 90^{\circ}\right)$ on 13 July 2010. The PMSEs power is in arbitrary scale.

Like Figure 1a, Figure 4a (for 14 July 2010) shows the variation of PMSEs intensity over the entire time interval (in this instance, 10:30-13:00). Figures 5 and 6 are similar to Figures 2 and 3, but for 14 July 2010. The PMSEs experiments began at 10:30 UT with a vertical elevation angle.

By comparing the experimental results shown in Figures 4 and 7 for 14 and 15 July 2010, respectively, it is clear that PMSEs exhibited a layered structure on both the $14^{\text {th }}$ and the $15^{\text {th }}$. There are, however, some differences between the PMSEs in the upper and lower layers. PMSEs on 15 July show a stronger intensity than those on the $14^{\text {th }}$. Nevertheless, PMSEs often disappear or weakens in some regions on both days. The PMSEs occurrence height on both days was, as a whole, lower than that on the $13^{\text {th }}$. PMSEs occurred higher than $90 \mathrm{~km}$ for a short time interval on 14 July (Figure 4a), but were lower than $90 \mathrm{~km}$ on 15 July (Figure 7a).

The variations of PMSEs power with elevation angle on 14 and 15 July are given in Figures 5 and 8, respectively. On 14 July the weakest echoes occured at elevation angle $90^{\circ}$ and the strongest echoes occured at $78^{\circ}$ (Figure 5), while on 15 July the strongest echoes occured at elevation angle $86^{\circ}$; PMSEs power at elevation angles $78^{\circ}, 82^{\circ}$ and $90^{\circ}$ were comparable (Figure 8). Mean PMSEs power versus time at different elevation angles on 14 and 15 July is presented in Figures 6 and 9, respectively. In these experiments, the radar was steered in $140 \mathrm{~s}$ increments; all the cycles in these two days were analyzed. Figures $5 \mathrm{a}$ and $8 \mathrm{a}$ show that the PMSEs power at elevation angle $78^{\circ}$ on 14 July and $86^{\circ}$ on 15 July were clearly higher than those at the other elevation angles. In other words, the strongest PMSEs on 14 and 15 July 2010 occurred at 

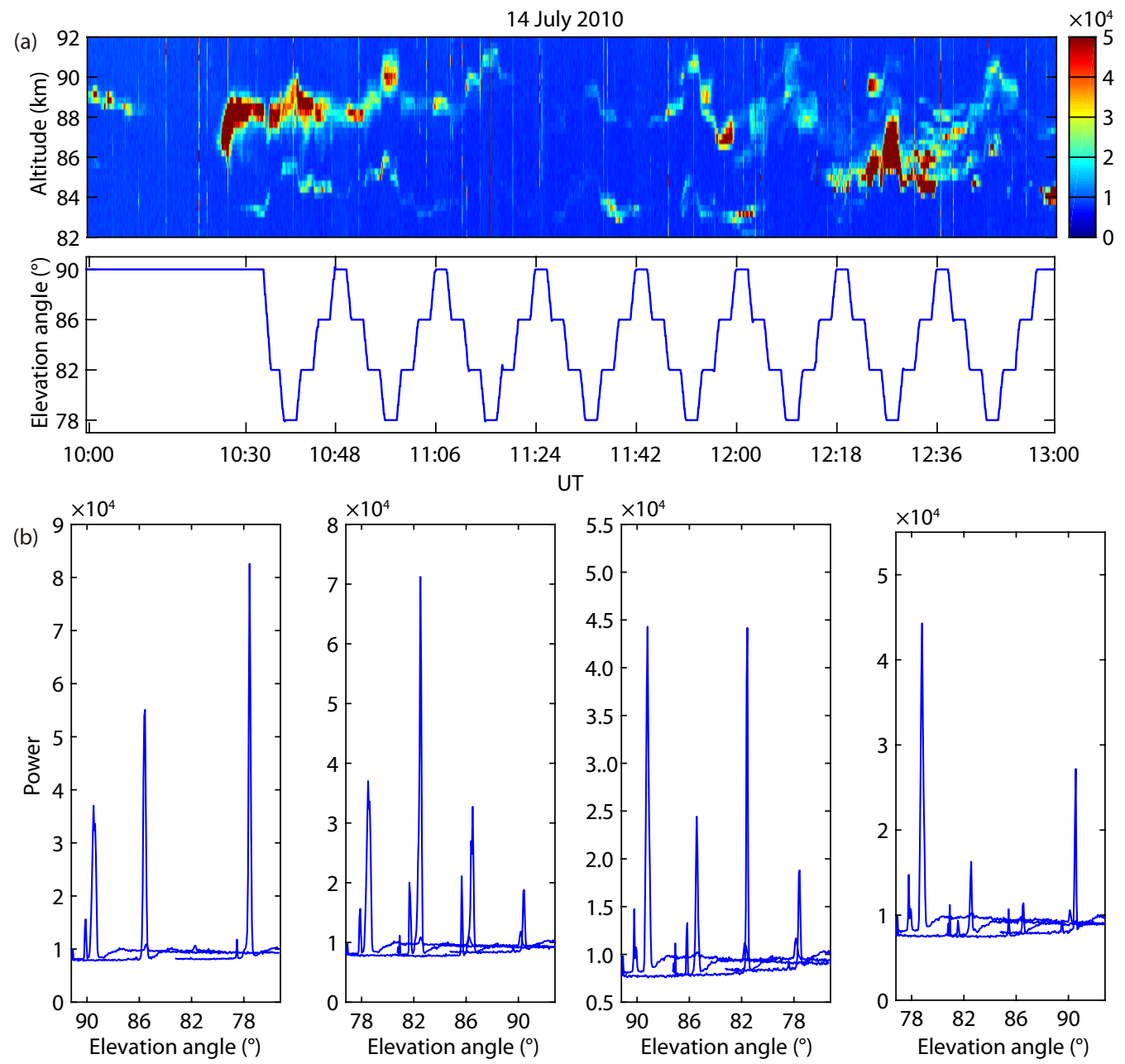

Figure 4. As in Figure 1, but for 10:30-13:00 UT on 14 July 2010. Note that in (b) the elevation angles vary from $78^{\circ} \rightarrow 90^{\circ}$.

off-vertical angles at the time of layered PMSEs events on those days, in agreement with observations on the previous day, 13 July 2010.

\section{Discussion}

By using PMSEs observations carried out with the EISCAT VHF radar on 13-15 July 2010, the characteristics of PMSEs observed at different elevation angles have been analyzed. Two different methods have been used for the analysis: (i) PMSEs power at different elevation angles (shown in Figures 2, 5, and 8) and (ii) the mean PMSEs power changing with time at different elevation angles (shown in Figures 3, 6, and 9). By using these two methods on the measurement days, it is shown that the PMSEs peak power and maximum mean PMSEs power occur at the same elevation angles. Also, PMSEs intensity is observed to exhibit a wide variation with altitude.

Figures 1a and 7a show that PMSEs have a distinct and stable double-layer structure; Figures $2 \mathrm{a}, 5 \mathrm{a}$ and $8 \mathrm{a}$ show the strongest PMSEs power occurred at elevation angles $86^{\circ}, 78^{\circ}$, and $86^{\circ}$, respectively on the three days of observation, but never on those days at the vertical angle $\left(90^{\circ}\right)$.

The observations of PMSEs using EISCAT VHF radar on 14 and 15
July 2010 were made at the same elevation angles and using the same modes. However, comparison of the results indicates that there were some differences between those two days. For example, the layered PMSEs structure was very unstable on 14 July, and the PMSEs power shows a large difference with different elevation angles. Note that the strongest PMSEs power did not occur at the vertical elevation angle. The exact cause of the double-layer structure is unknown, but there may be layered dusty plasma or double-layer irregularities in the polar mesopause, and the origins of both mechanisms are different. Czechowsky et al. (1988) and Ma ZZ et al. (2013) have investigated this issue, but their conclusions are not consistent. In addition, compared with $\mathrm{Li} \mathrm{H}$ et al. (2018), we noticed that layered PMSEs appeared in our data and analyzed the characteristics of layered PMSEs at different elevation angles. We use a different perspective to explain the experimental results and give a better quantitative understanding of the overall reflection and scatter processes. By analyzing the relations between the strongest radar echo and the associated elevation angle, we obtain a distribution of the strongest radar echo at different antenna elevation angles and the characters of PMSEs observed with different elevation angles at VHF.

To study further the variation of radar echoes at different eleva- 

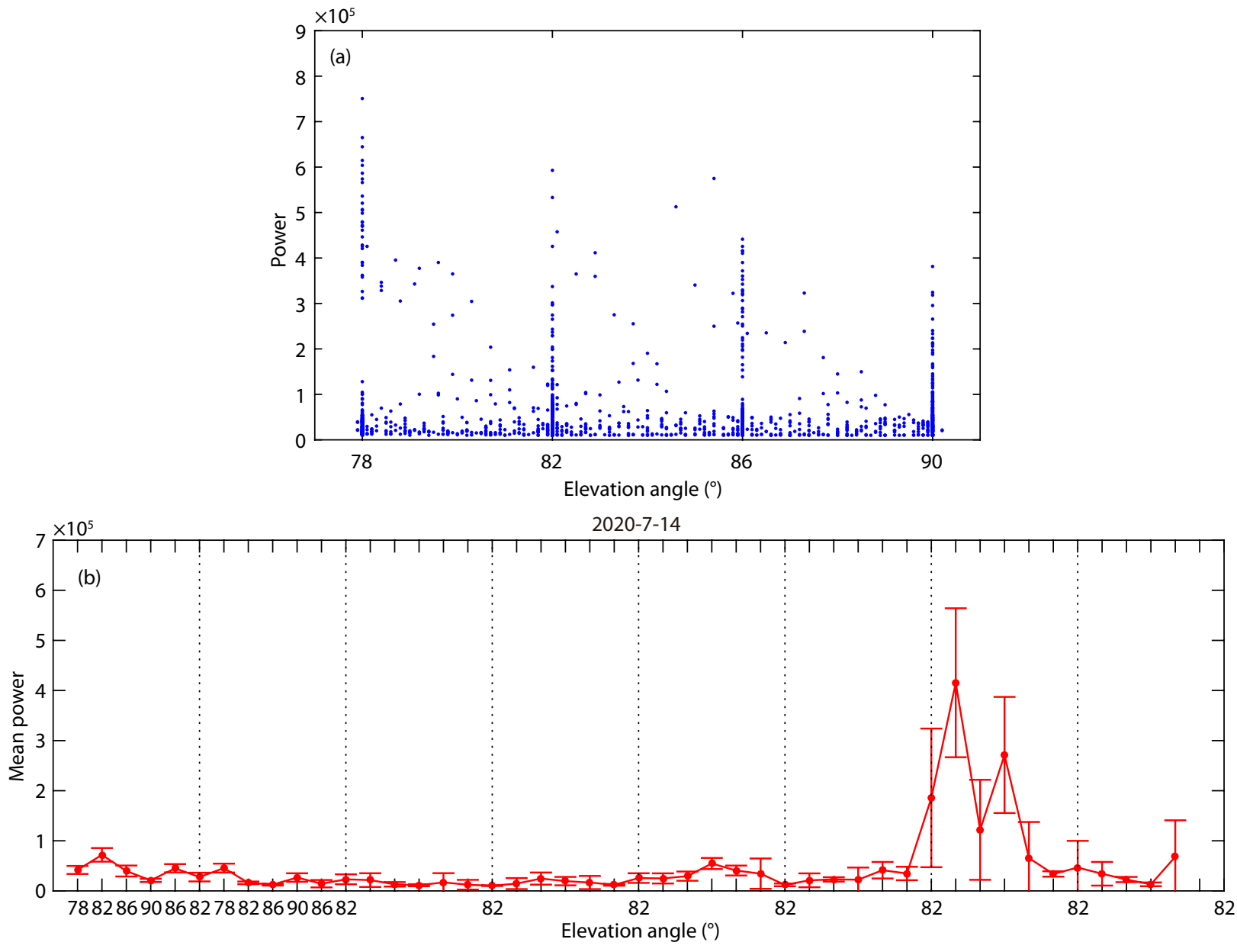

Figure 5. As in Figure 2, but for 14 July 2010.

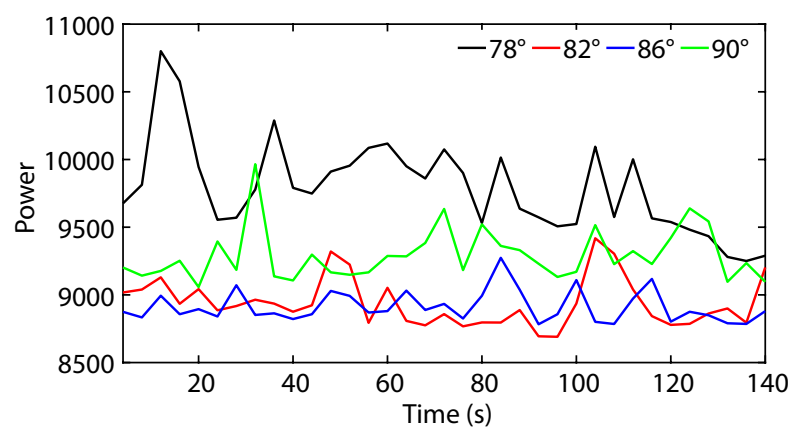

Figure 6. As in Figure 3, but for 14 July 2010.

tion angles, we have analyzed the relation between PMSEs backscatter (peak and lowest) power intensity and elevation angles, as shown in Figure 10. First we normalize the experimental period of each angle, then find the statistical relations between the strongest radar echoes and the elevation angles (Figure 10, blue line) and between the weakest radar echoes and the elevation angles (Figure 10, red line) of our 39 experimental periods. The jump observed in the elevation angle over the period 1-15 in the horizontal axis of Figure 10 is for 13 July 2010, as the lowest elevation angle was $84^{\circ}$. The elevation angles jump periods $16-31$ and 32-39 are for 14 and 15 July, respectively. It can be seen that the radar echo power varies greatly with elevation angle. Moreover, successive cycles are not highly correlated, suggesting that the environment was rapidly changing in polar mesopause. Longterm observations may yield better results.

We analyzed systematically the distribution probability of the strongest radar echoes at different elevation angles during 13-15 July 2010. Figure 11 shows the distribution probability of the peak radar power corresponding to different elevation angles on 13-15 July. Since the elevation angles of our experiment are mainly concentrated at $78^{\circ}, 82^{\circ}, 84^{\circ}, 86^{\circ}, 88^{\circ}$ and $90^{\circ}$, we focus our description on those angles. It can be seen that the elevation angles corresponding to the maximum probability of the peak power do not correspond to the vertical angle but to elevation angles $78^{\circ}$ or $86^{\circ}$. Nevertheless, the probability of the strongest radar echo occurring at the elevation angle $90^{\circ}$ is still nonnegligible. Note also, that the echo intensity is not evenly distributed at each radar antenna elevation angle.

It can also be concluded from Figure 11 that the occurrence rate of the peak power obtained at the vertical angle is not very high, whether the period is a single-day or three-days. Woodman and Chu (1989) have suggested that the off-vertical angle feature might be caused by an anisotropic scattering process. Sommer et al. (2016b) proposed that anisotropic scattering is not the main 

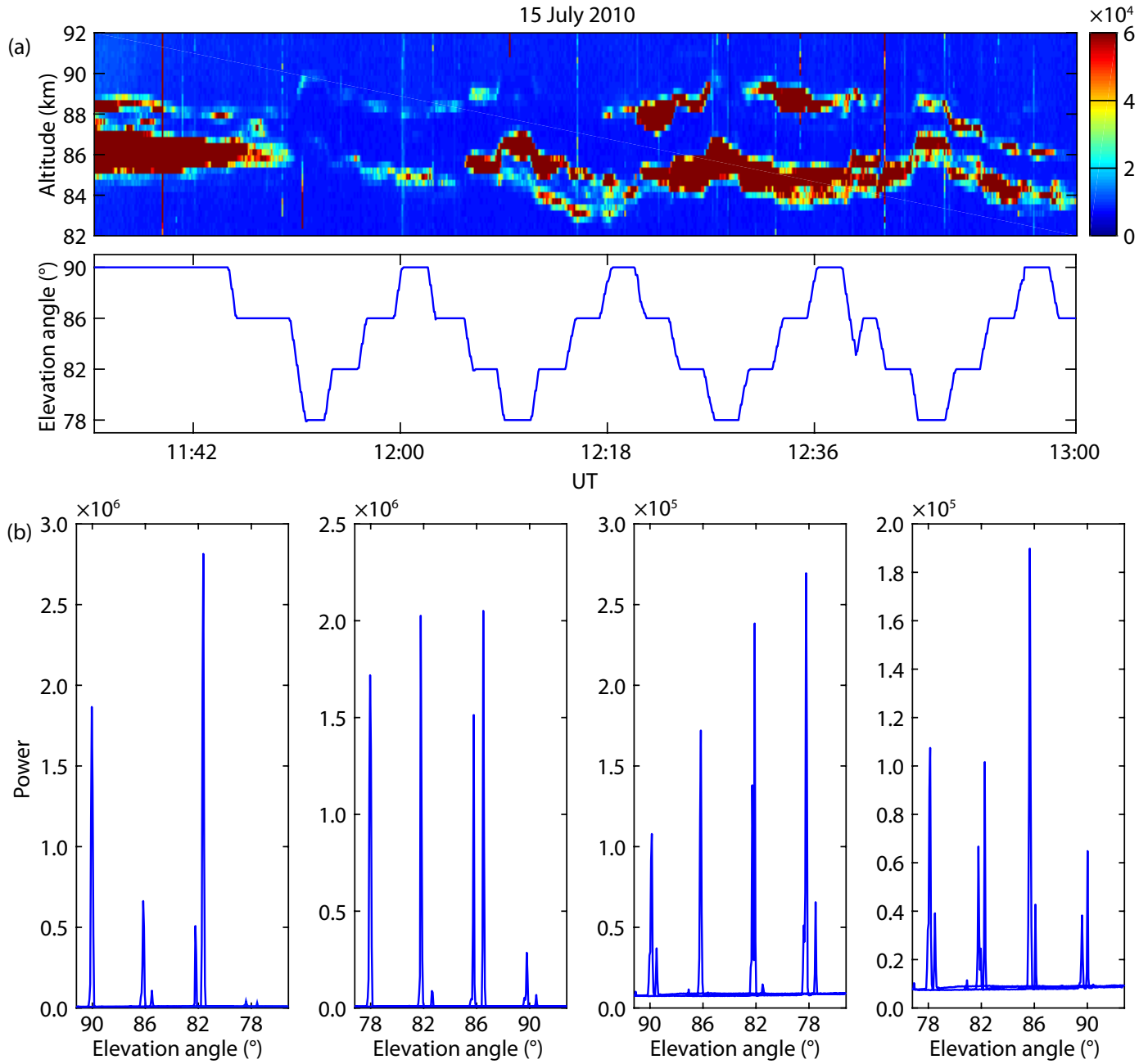

Figure 7. As in Figure 4 but for 11:42-13:00 UT on 15 July 2010.

cause, but that variability inside the vertical beam may play an explanatory role. PMSEs consist of nonhomogeneous isotropic scattering. The collision frequency is very large, and wind shear is one of the important factors that may cause anisotropy at 82-92 km, but still further theoretical analysis and experimental observations are needed. We also consider that there may be irregularly tilted PMSEs dust layers with boundary scales of different sizes. Due to the different tilt angles, electromagnetic waves can be reflected or scattered in different directions. These make the process more complex; further research is required. It is indicated that the PMSEs dust layer has an angular dependence on the reflection or scattering direction of the electromagnetic waves transmitted by the radar, and that there is inhomogeneous scattering at some of the angles.

The theory of turbulent volume isotropic scatters has been applied to explain some types of PMSEs events (e.g. Kelley et al., 1990; La Hoz et al., 2006). Nevertheless, not all types of PMSEs events can be explained by the turbulent volume isotropic scatter theory (e.g. Lübken et al., 2002; Belova et al., 2007). Differences in the characteristics of PMSEs at different elevation angles imply that the scattering structure cannot be purely isotropic. A combination of two classical extreme models in the middle atmosphere (turbulent volume isotropic scatter and specular Fresnel reflec- tion) may be helpful to explain the experimental results, which suggest that there is an anisotropic scattering mechanism (such as Specular Fresnel Reflection) when the inclined angle is increased, and the echo intensity is decreasing. Concerning the observations in this paper, the suggestion is that specular Fresnel reflection probably can be used to explain the results on 13-15 July 2010. However, this suggestion still needs to be confirmed.

The experimental method used in this paper still has some weaknesses linked to the fact that the observed phenomena may be different at different elevation angles even on the same day. It is well known that the background environment is very complex, and the condition inside and around experimental objects can be easily affected. Even if PMSEs regions in the mesopause are not disturbed during the experiment time, objects detected by EISCAT VHF radar at different elevation angles may be different. When we assume that the occurrence altitude of a PMSEs is $88 \mathrm{~km}$ and EISCAT VHF radar works at elevation angles $90^{\circ}$ and $88^{\circ}$, respectively, the horizontal distance difference at $88 \mathrm{~km}$ is $3.1 \mathrm{~km}$. When EISCAT VHF radar works at $90^{\circ}$ and $78^{\circ}$, the horizontal distance difference at $88 \mathrm{~km}$ is $18.7 \mathrm{~km}$ (see Table 1). Though different features may be observed at different elevation angles, and the results will have some deviations, we are confident that the data in the three-days experiments are representative and the res- 

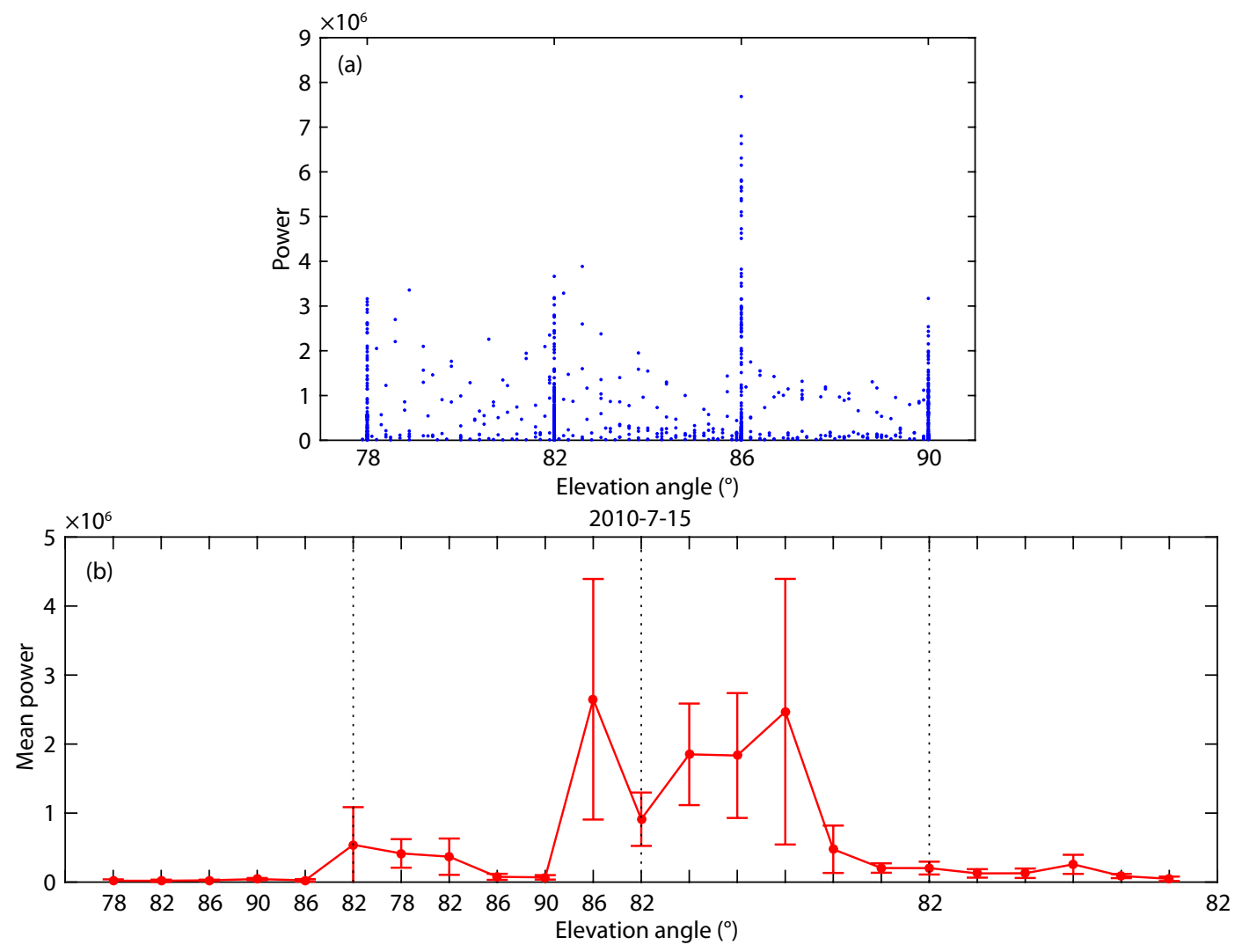

Figure 8. As in Figure 5, but for 15 July 2010.

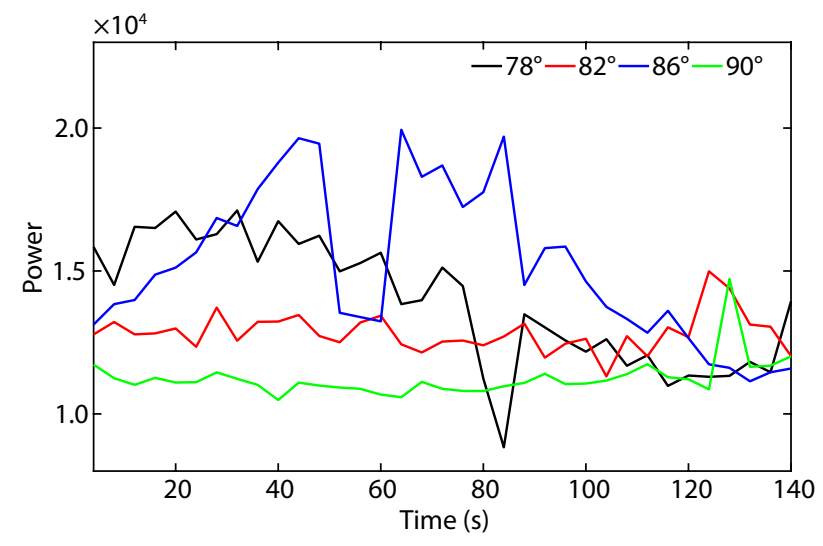

Figure 9. As in Figure 6, but for 15 July 2010.

ults can be trusted.

\section{Conclusions}

We have described the PMSEs experiments by EISCAT VHF $224 \mathrm{MHz}$ radar at different elevation angles from $78^{\circ}$ to $90^{\circ}$ on 13-15 July 2010. By exploring the experimental results, we have found that the PMSEs peak power and maximum PMSEs average power occur at the same elevation angles. However, other PMSEs intensities do not have one-to-one correspondence with elevation angles. Homogeneous isotropic turbulence cannot absolutely explain the characteristics of PMSEs with different elevation angles. In addition, when layered PMSEs events occur, the strongest echoes do not occur at the vertical elevation angle, in- dicating that the strongest echo directions often occur in the offvertical direction when there are layered PMSEs. The PMSEs phenomenon is both specular and isotropic, which is influenced by background dynamics causing the gap formation. The experimental results suggest that reflection plays a stronger role in the case of layered PMSEs. In future work, it should be possible to achieve a more holistic understanding of the PMSEs phenomenon, if more in situ PMSEs measurements become available. The process and probe into the nature of the mechanism of PMSEs generation can then be better realized.

\section{Acknowledgments}

We are grateful to the EISCAT Scientific Association and the China Research Institute of Radiowave Propagation (CRIRP) for providing the PMSEs experimental data. The EISCAT Scientific Association is supported by China (China Research Institute of Radiowave Propagation), Finland (Suomen Akatemia of Finland), Japan (the National Institute of Polar Research of Japan and Institute for Space-Earth Environmental Research at Nagoya University), Norway (Norges Forkningsrad of Norway), Sweden (the Swedish Research Council), and the UK (the Natural Environment Research Council). We also acknowledge the China Scholarship Council. This research was funded by the National Natural Science Foundation of China (No.s 61671116, 61771096, 11905026), National Key Research and Development Program of China (No. 2019YFA0210202) and Fundamental Research Funds for the Central Universities (No.s ZYGX2019Z006, ZYGX2019J012). 


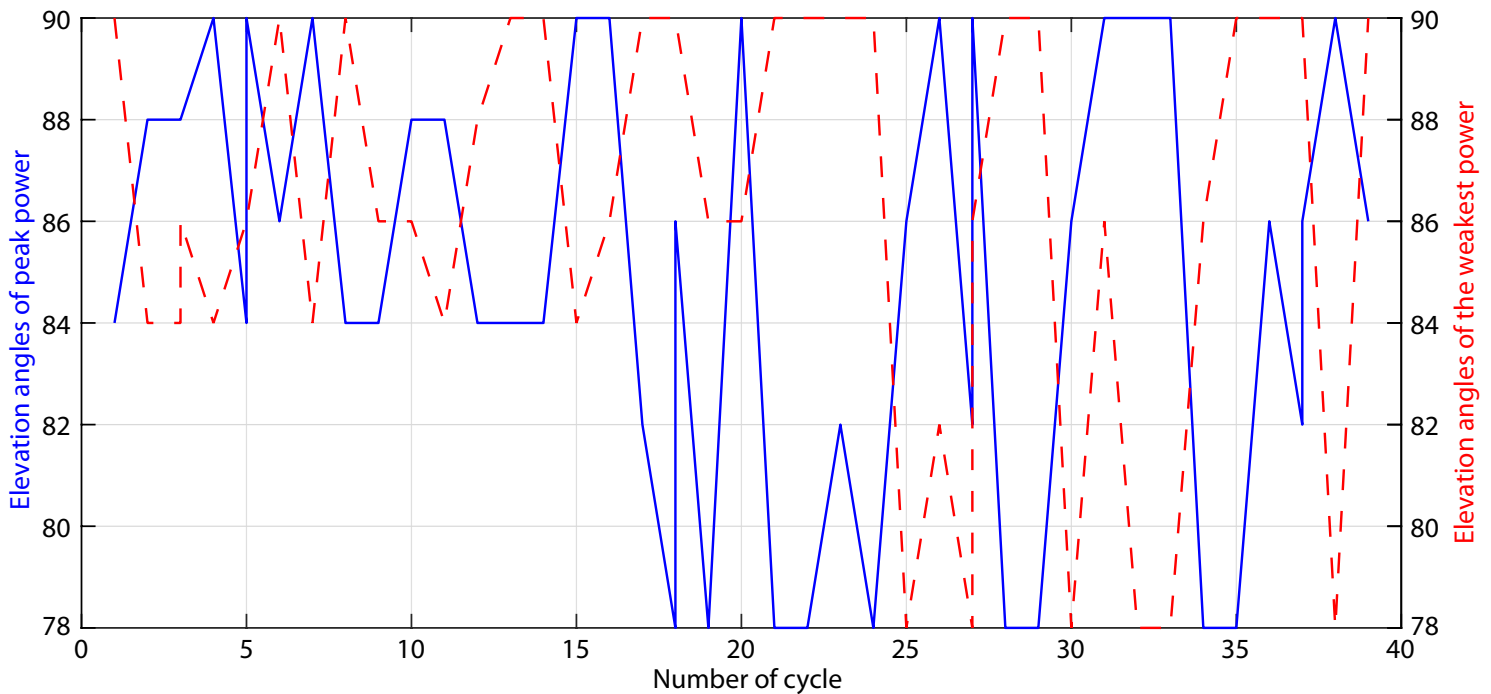

Figure 10. Relation between PMSE backscatter peak (blue solid line) and weakest (red dotted line) power intensity and elevation angles during 13,14 and 15 July 2010.
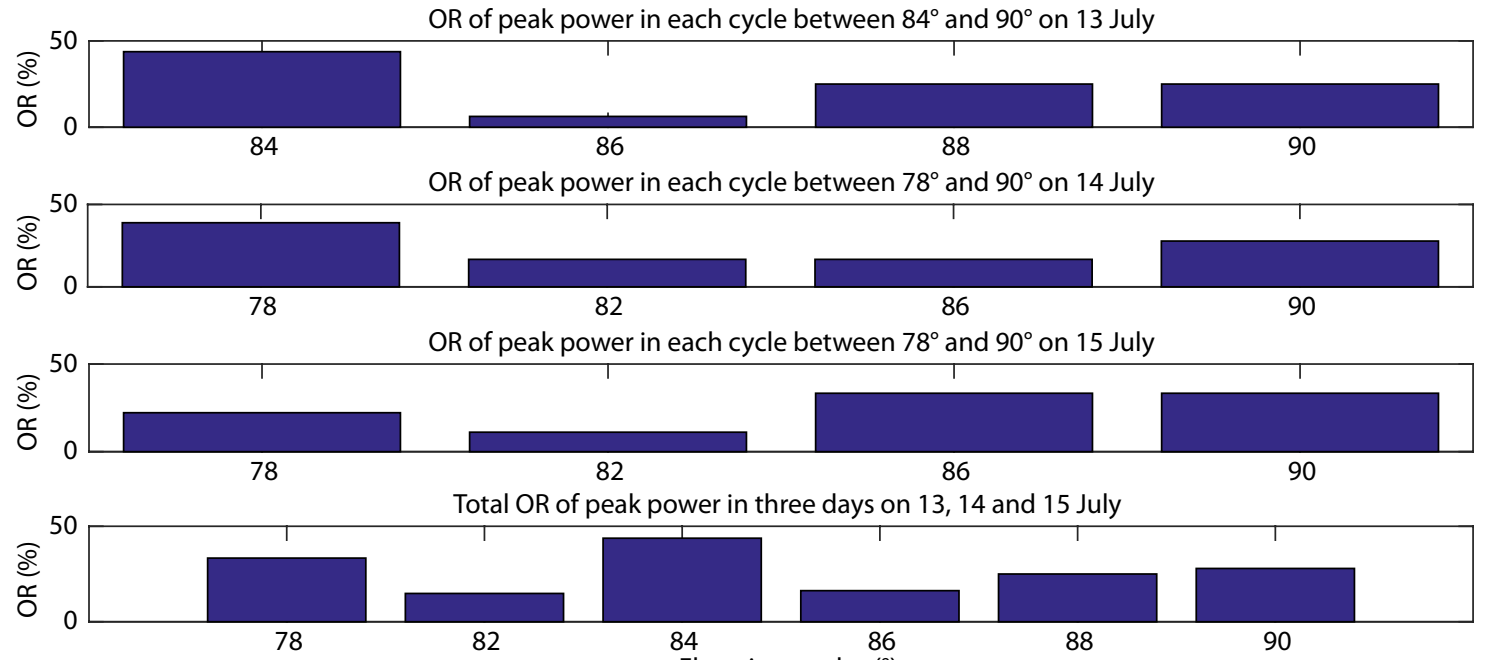

Figure 11. The occurrence rate (OR) of the peak PMSE backscatter power at different elevation angles. The four panels from top to bottom represent the results on $13,14,15$ and total 13-15 July, respectively.

Table 1. Horizontal distances at different elevation angles when PMSE occur at $88 \mathrm{~km}$.

\begin{tabular}{ccc}
\hline Elevation angle & Rotation angle & Horizontal distance \\
\hline $90^{\circ}$ & $0^{\circ}$ & $0 \mathrm{~km}$ \\
$88^{\circ}$ & $2^{\circ}$ & $3.1 \mathrm{~km}$ \\
$86^{\circ}$ & $4^{\circ}$ & $6.2 \mathrm{~km}$ \\
$84^{\circ}$ & $6^{\circ}$ & $9.2 \mathrm{~km}$ \\
$82^{\circ}$ & $8^{\circ}$ & $12.4 \mathrm{~km}$ \\
$78^{\circ}$ & $12^{\circ}$ & $18.7 \mathrm{~km}$ \\
\hline
\end{tabular}

\section{Data Availability}

All EISCAT data used in this work can be downloaded at https://www.eiscat.se/schedule/schedule.cgi. The EISCAT radar observation data will be publicly available via EISCAT Scientific Association on a project-agreed schedule.

\section{References}

Belova, E., Dalin, P., and Kirkwood, S. (2007). Polar mesosphere summer echoes: a comparison of simultaneous observations at three wavelengths. Ann. Geophys., 25(12), 2487-2496. https://doi.org/10.5194/angeo-25-2487-2007 Bremer, J., Hoffmann, P., Höffner, J., Latteck, R., Singer, W., Zecha, M., and Zeller, O. (2006). Long-term changes of mesospheric summer echoes at polar and middle latitudes. J. Atmos. Sol. Terr. Phys., 68(17), 1940-1951. https://doi.org/10.1016/j.jastp.2006.02.012

Chau, J. L., Röttger, J., and Rapp, M. (2014). PMSE strength during enhanced D region electron densities: Faraday rotation and absorption effects at VHF frequencies. J. Atmos. Sol. Terr. Phys., 118, 113-118. https://doi.org/10.1016/j.jastp.2013.06.015

Chilson, P., Yu, T. Y., Palmer, R., and Kirkwood, S. (2002). Aspect sensitivity measurements of polar mesosphere summer echoes using coherent radar 
imaging. Ann. Geophys., 20(2), 213-223. https://doi.org/10.5194/angeo-20213-2002

Czechowsky, P., Reid, I. M., and Rüster, R. (1988). VHF radar measurements of the aspect sensitivity of the summer polar mesopause echoes over Andenes $\left(69^{\circ} \mathrm{N}, 16^{\circ} \mathrm{E}\right)$, Norway. Geophys. Res. Lett., 15(11), 1259-1262. https://doi.org/10.1029/GL015i011p01259

Ecklund, W. L., and Balsley, B. B. (1981). Long-term observations of the Arctic mesosphere with the MST radar at Poker Flat, Alaska. J. Geophys. Res.: Space Phys., 86(A9), 7775-7780. https://doi.org/10.1029/JA086iA09p07775

Hocking, W. K., Rüster, R., and Czechowsky, P. (1986). Absolute reflectivities and aspect sensitivities of VHF radio wave scatterers measured with the SOUSY radar. J. Atmos. Terr. Phys., 48(2), 131-144. https://doi.org/10.1016/00219169(86)90077-2

Kelley, M. C., Ulwick, J. C., Röttger, J., Inhester, B., Hall, T., and Blix, T. (1990). Intense turbulence in the polar mesosphere: rocket and radar measurements. J. Atmos. Terr. Phys., 52(10-11), 875-891. https://doi.org/10.1016/0021-9169(90)90022-F

Lübken, F. J., Rapp, M., and Hoffmann, P. (2002). Neutral air turbulence and temperatures in the vicinity of polar mesosphere summer echoes. $J$. Geophys. Res.: Atmos., 107(D15), ACL 9-1-ACL 9-10. https://doi.org/10.1029/2001JD000915

La Hoz, C., Havnes, O., Næsheim, L. I., and Hysell, D. L. (2006). Observations and theories of Polar Mesospheric Summer Echoes at a Bragg wavelength of 16 cm. J. Geophys. Res.: Atmos., 111 (D4), D04203. https://doi.org/10.1029/2005JD006044

La Hoz, C., Pinedo, H., Havnes, O., Kosch, M. J., Senior, A., and Rietveld, M. T. (2014). First measurements of aspect sensitivity of polar mesospheric summer echoes by a bistatic radar system. In AGU Fall Meeting Abstracts. Washington: AGU.

Li, H., Wu, J., Tian, R. H., Jiang, X. N., and Liang, Y. G. (2018). Aspect sensitivity of polar mesosphere summer echoes observed with the EISCAT VHF radar. Adv. Polar Sci., 29(1), 34-39. https://doi.org/10.13679/j.advps.2018.1.00034

Li, Q., and Rapp, M. (2013). PMSE observations with the EISCAT VHF- and UHFradars: Ice particles and their effect on ambient electron densities. J. Atmos. Sol. Terr. Phys., 104, 270-276. https://doi.org/10.1016/j.jastp.2012.10.015

Ma, Z. Z., Xu, B., Wu, J., Xu, Z. W., and Wu, J. (2013). VHF radar observations of the PMSE over Norway. Chin. J. Radio Sci. (in Chinese), 28(1), 1-6. https://doi.org/10.13443/j.cjors.2013.01.016

Pfaff, R., Holzworth, R., Goldberg, R., Freudenreich, H., Voss, H., Croskey, C., Mitchell, J., Gumbel, J., Bounds, S., ... Latteck, R. (2001). Rocket probe observations of electric field irregularities in the polar summer mesosphere. Geophys. Res. Lett., 28(8), 1431-1434. https://doi.org/10.1029/2000GL012677
Reid, I. M., Rüster, R., Czechowsky, P., and Schmidt, G. (1988). VHF radar measurements of momentum flux in the summer polar mesosphere over Andenes $\left(69^{\circ} \mathrm{N}, 16^{\circ} \mathrm{E}\right)$, Norway. Geophys. Res. Lett., 15(11), 1263-1266. https://doi.org/10.1029/GL015i011p01263

Smirnova, M., Belova, E., Kirkwood, S., and Mitchell, N. (2010). Polar mesosphere summer echoes with ESRAD, Kiruna, Sweden: Variations and trends over 1997-2008. J. Atmos. Sol. Terr. Phys., 72(5-6), 435-447. https://doi.org/10.1016/j.jastp.2009.12.014

Smirnova, M., Belova, E., and Kirkwood, S. (2011). Polar mesosphere summer echo strength in relation to solar variability and geomagnetic activity during 1997-2009. Ann. Geophys., 29(3), 563-572. https://doi.org/10.5194/angeo-29-563-201

Smirnova, M., Belova, E., and Kirkwood, S. (2012). Aspect sensitivity of polar mesosphere summer echoes based on ESRAD MST radar measurements in Kiruna, Sweden in 1997-2010. Ann. Geophys., 30(3), 457-465. https://doi.org/10.5194/angeo-30-457-2012

Sommer, S., Chau, J. L., and Schult, C. (2016a). On high time-range resolution observations of PMSE: Statistical characteristics. J. Geophys. Res.: Atmos., 121(12), 6713-6722. https://doi.org/10.1002/2015JD024531

Sommer, S., Stober, G., and Chau, J. L. (2016b). On the angular dependence and scattering model of polar mesospheric summer echoes at VHF. J. Geophys. Res.: Atmos., 121(1), 278-288. https://doi.org/10.1002/2015JD023518

Swarnalingam, N., Hocking, W. K., and Drummond, J. R. (2011). Long-term aspect-sensitivity measurements of polar mesosphere summer echoes (PMSE) at Resolute Bay using a $515 \mathrm{MHz}$ VHF radar. J. Atmos. Sol. Terr. Phys., 73(9), 957-964. https://doi.org/10.1016/j.jastp.2010.09.032

Woodman, R. F., and Chu, Y. H. (1989). Aspect sensitivity measurements of VHF backscatter made with the Chung-Li radar: Plausible mechanisms. Radio Sci., 24(2), 113-125. https://doi.org/10.1029/RS024i002p00113

Yi, W., Reid, I. M., Xue, X. H, Younger, J. P., Spargo, A. J., Murphy, D. J., Chen, T. D., and Dou, X. K. (2017). First observation of mesosphere response to the solar wind high-speed streams. J. Geophys. Res.: Space Phys., 122(8), 9080-9088. https://doi.org/10.1002/2017JA024446

Yi, W., Reid, I. M., Xue, X. H., Murphy, D. J., Hall, C. M., Tsutsumi, M., Ning, B. Q., Li, G. Z., Younger, J. P., ... Dou, X. K. (2018). High-and middle-latitude neutral mesospheric density response to geomagnetic storms. Geophys. Res. Lett., 45(1), 436-444. https://doi.org/10.1002/2017GL076282

Zecha, M., Röttger, J., Singer, W., Hoffmann, P., and Keuer, D. (2001). Scattering properties of PMSE irregularities and refinement of velocity estimates. J. Atmos. Sol. Terr. Phys., 63(2-3), 201-214. https://doi.org/10.1016/S13646826(00)00182-6 